\title{
Efektivitas Pendidikan Keterampilan Bagi Remaja dalam Upaya Pendewasaan Usia Perkawinan di Kecamatan Kediri Kelompok Dialog Warga Desa Jagaraga Indah
}

\author{
Mulyadi Fadjar \\ Widyaiswara Ahli Muda Bapelkes Provinsi NTB \\ Email: mulyadifadjar930@gmail.com. Alamat: Jl. Alamanda V/G.394 Wisma Sweta Indah, 83233
}

\begin{abstract}
DW-PUP groups using the DW Method involve active participation of the village community, providing motivation to prevent early marriage in the village. Support, policy synergy and funds from the Provincial, Regency / City to Village Governments resulted in an average first marriage age of 0.12 years; 2016 (20.15 years) and 2017 (20.27 years). Based on Susenas data in 2018, the average age at marriage for women per Regency / City of NTB Province shows a declining trend, in 2017 (20.27 years), 2018 (20.23 years) and 2019 (20.21 years). PUP efforts carried out by the NTB Provincial Government through the NTB Province P3AP2KB Office at the end of 2018 are activities to increase human resources, especially adolescents under 21 years. Skills Education Activities for Adolescents are PUP's efforts through the provision of knowledge, skills and awareness raising towards the age of marriage. The design in this study used a descriptive method with a qualitative approach. The research sample, all PKBR participants, totaling 20 respondents, used the PUP Effort Perception Questionnaire Sheet, Structured Interview Guide and Document Tracing Form. The results of the study, the incompatibility of the implementation with the intended targets, caused the PKBR's goals not to be achieved, so that PKBR became ineffective towards PUP efforts in Jagin Village. The failure to achieve the PKBR goals set, so that it has not been able to provide strengthening skills for youth economic development in the PUP effort. Based on the research results, it is necessary to have training guidelines and curricula to obtain a consistent, controlled process in the stages of the implementation process with measurable results. It is necessary to have coordination and cooperation with parties that are directly related to the target activities.
\end{abstract}

Keywords : Citizen Dialogue; Maturity Of Marriage

Abstrak. Kelompok DW-PUP dengan Metode DW melibatkan peran serta aktif masyarakat desa, memberikan motivasi mencegah terjadinya perkawinan dini di desa. Dukungan, sinergitas kebijakan dan dana dari Pemerintah Provinsi, Kabupaten/Kota sampai ke Desa menghasilkan capaian rata-rata usia kawin perempuan pertama sebesar 0,12 tahun; 2016 (20,15 th) dan tahun 2017 (20,27 th). Berdasarkan data Susenas tahun 2018, capaian rata-rata usia kawin I perempuan per Kabupaten/Kota Provinsi NTB menunjukkan trend yang menurun, tahun 2017 (20,27 th), 2018 (20,23 th) dan 2019 (20,21 th). Upaya PUP yang dilaksanakan Pemerintah Provinsi NTB melalui Dinas P3AP2KB Provinsi NTB pada akhir tahun 2018 adalah kegiatan meningkatkan sumber daya manusia, khususnya remaja dibawah 21 tahun. Kegiatan Pendidikan Keterampilan Bagi Remaja merupakan upaya PUP melalui pemberian bekal pengetahuan, keterampilan dan penumbuhan kesadaran kepada usia menikah. Rancangan dalam penelitian ini menggunakan metode deskriptif dengan pendekatan kualitatif. Sampel penelitian, 20 responden peserta PKBR dan 1 informan kunci, menggunakan instrumen Lembar Kuesioner Persepsi Upaya PUP, Panduan Wawancara Terstruktur dan Formulir Penelusuran Dokumen. Hasil penelitian, ketidak sesuaian pelaksanaan dengan sasaran yang dituju, menyebabkan tidak tercapainya tujuan PKBR, sehingga PKBR menjadi tidak efektiv terhadap upaya PUP di Desa Jagin. Ketidak berhasilan mencapai tujuan PKBR yang ditetapkan, sehingga belum mampu memberikan penguatan keterampilan untuk pembangunan ekonomi remaja dalam upaya PUP. Berdasarkan hasil penelitian, diperlukan adanya panduan dan kurikulum pelatihan untuk mendapatkan proses yang konsisten, terkendali dalam tahapan proses pelaksanaannya dengan hasil yang terukur. Diperlukan adanya koordinasi dan kerjasama dengan pihak-pihak yang berhubungan langsung dengan sasaran kegiatan.

Kata Kunci : Dialog Warga; Pendewasaan Usia Perkawinan. 


\section{PENDAHULUAN}

Nusa Tenggara Barat, provinsi pertama yang mengatur Pendewasaan Usia Perkawinan (PUP) (Tempo.Co, 2015) ${ }^{1}$ yang merupakan program unggulan, karena banyaknya masalah pendidikan dan kesehatan yang disebabkan oleh perkawinan usia dini (GEN, 2017) ${ }^{2}$. Gubernur Provinsi NTB menerbitkan Surat Edaran nomor 150/1138/Kum, tentang PUP, tertanggal 12 Juni 2014 dengan Usia Kawin Pertama (UKP) menikah bagi laki-laki dan perempuan minimal 21 tahun (NTB, Pemprov, 2014) 3 . Dinas Pemberdayaan Perempuan, Perlindungan Anak, Pengendalian Penduduk dan Keluarga Berencana (DP3AP3KB) Provinsi NTB melakukan pendekatan masyarakat dengan Metode Dialog Warga (Metode DW) serta sosialisasi melalui kerjasama dengan forum remaja, LSM serta dukungan Deutsche Gesellschaft für Internationale Zusammenarbeit (GIZ) yang merupakan perusahaan internasional milik Pemerintah Federal Jerman yang beroperasi di berbagai bidang (BP3AKB P. N., 2015) ${ }^{4}$. Kelompok DW-PUP dengan Metode DW yang melibatkan peran serta aktif seluruh komponen masyarakat desa, memberikan motivasi tersendiri dalam upaya untuk mencegah terjadinya perkawinan dini di desanya. Adanya dukungan, sinergitas kebijakan dan dana dari unsur Pemerintah Provinsi, Kabupaten/Kota sampai ke Desa menghasilkan capaian rata-rata usia kawin perempuan pertama tahun sebesar 0,12 tahun; 2016 (20,15 th) dan tahun 2017 (20,27 th) (BP3AKB G.-S. , 2011).

Data Susenas tahun 2018, capaian rata-rata usia kawin I perempuan per Kabupaten/Kota Provinsi NTB menunjukkan trend menurun, tahun 2017 (20,27 th), tahun 2018 (20,23 th) dan tahun 2019 (20,21 th). Upaya PUP yang dilaksanakan adalah kegiatan untuk meningkatkan potensi remaja yang berumur dibawah 21 tahun. Program "Pengembangan Kelompok DW di Masyarakat dalam Rangka Peningkatan Keterampilan Remaja" dalam bentuk kegiatan Pendidikan Keterampilan Bagi Remaja (PKBR), pemberian bekal pengetahuan, keterampilan dan penumbuhan kesadaran usia menikah. PKBR dalam rangka peningkatan perekonomian, antara lain dilakukan Kelompok DW Desa Jagaraga Indah (Jagin) dalam upaya PUP di Kecamatan Kediri, melalui pendidikan kewirausahaan dan keterampilan sebagai salah satu sumber mata pencaharian. Mengikut sertakan para remaja dalam pelatihan. Hasil yang diharapkan adalah diperolehnya keterampilan dalam berusaha untuk menuju kelayakan ekonomi keluarga. (PPKB, Bidang, 2018) ${ }^{6}$. Variabel efektivitas melihat pencapaian tujuan PKBR berdasarkan persepsi peserta PKBR dan kesesuaian dengan sasaran yang dituju terhadap upaya PUP di Desa Jagin dan variabel PUP sebagai upaya anggota Kelompok DW Desa Jagin untuk menunda kawin pertama.

PUP sebagai salah satu upaya mencegah terjadinya pernikahan dini banyak dilaksanakan: (Mazdaif, 2014) ${ }^{7}$ Ada Pengaruh hasil penyuluhan PUP terhadap sikap tentang pernikahan pada siswa kls. XI SMAN I Dlingo Bantul dengan mempelajari sikap remaja terhadap pernikahan dini. (Puji Lestari, 2017) ${ }^{8}$ mengetahui strategi yang digunakan oleh Dinas PP-KB melihat faktor penghambat dan faktor pendukung terjadinya pernikahan dini, dalam Mengkampanyekan Pendewasaan Usia Perkawinan terhadap remaja Ponorogo. (Sumerah, 2019) ${ }^{9}$ melihat peran nilai adat merupakan modal sosial untuk merawat harmonisasi sosial, dalam Penerapan regulasi usia kawin secara kualitatif, antropologi hukum, tradisi jampi pengikat. Dalam penelitian ini, akan mempelajari efektivitas PKBR berdasarkan persepsi peserta dan kesesuaian dengan sasaran yang dituju terhadap upaya PUP yang dilaksanakan pada Kelompok DW di Desa Jagin, Kecamatan Kediri. Sampai saat ini sangat terbatas yang melakukan penelitian terkait upaya PUP yang berfokus pada Kelompok DW.

Manfaat penelitian bagi instansi penyelenggara, sebagai informasi ketercapaian tujuan dari PKBR Kelompok DW, yaitu mendapatkan dukungan sosial bagi anak-anak remaja usia dibawah 21 tahun dalam rangka peningkatan usia perkawinan dan bahan pertimbangan tindak-lanjut kegiatan berikutnya dalam upaya memberikan penguatan dan motivasi pada remaja Kelompok DW Desa Jagin. Penelitian dilakukan sebagai tindak lanjut penelitian sebelumnya untuk meningkatkan kegiatan ekonomi Kelompok DW di masing-masing desa (Fadjar, Evaluasi Metode Dialog Warga dalam Upaya Meningkatkan Usia Kawin I Perempuan di Provinsi NTB, 2019) ${ }^{10}$ untuk melengkapi kebutuhan data dalam advokasi pembuatan Perda PUP Provinsi NTB. Tujuan penelitian ini untuk mengetahui efektivitas PKBR dalam upaya PUP Kelompok DW, Desa Jagin di Kecamatan Kediri. 


\section{METODE PENELITIAN}

Rancangan dalam penelitian ini menggunakan metode deskriptif untuk membuat gambaran tentang suatu keadaan secara objektif, menjawab permasalahan yang sedang dihadapi (Notoatmodjo S. , 2012) ${ }^{11}$ dengan pendekatan kualitatif di Desa Jagin dari tanggal 1 - 25 Juli 2020 Sampel penelitian, seluruh peserta PKBR yang berjumlah 20 responden dan Kepala Desa Jagin sebagai informan kunci. Menggunakan instrumen Lembar Kuesioner Persepsi Upaya PUP, Panduan Wawancara Terstruktur dan Formulir Penelusuran Dokumen. Kuesioner adalah sejumlah pertanyaan tertulis yang digunakan untuk memperoleh informasi dari responden dalam arti laporan tentang pribadinya, atau hal-hal yang ia ketahui (Arikunto, 2006) ${ }^{12}$. Menggunakan kuesioner persepsi upaya PUP yang telah dilakukan tahapan validitas \& reabilitasnya, diisi oleh 20 responden dengan kriteria penilaian "Baik, cukup, kurang" dengan nilai baik= 33-48, cukup= 17-32 dan kurang= 0-16.

Panduan wawancara terstruktur untuk klarifikasi data pada ketua kelompok peserta PKBR dan Kepala Desa sebagai informan kunci dan stakeholders program di desa. Definisi operasional suatu unsur penelitian yang menjelaskan bagaimana cara menentukan suatu variabel dan mengukur suatu variabel, sehingga definisi operasional ini merupakan suatu informasi ilmiah yang akan membantu peneliti lain yang ingin menggunakan variabel yang sama (Setiadi, 2007) ${ }^{13}$. Efektivitas yaitu Pencapaian tujuan PKBR berdasarkan persepsi peserta PKBR dan kesesuaian dengan sasaran yang dituju terhadap upaya PUP di Desa Jagin dan Pendewasaan Usia Perkawinan yaitu Upaya anggota Kelompok DW Desa Jagin untuk menunda kawin pertama.

Pemeriksaaan data dari lembar kuesioner, wawancara sebagai tahap triangulasi narasumber. Mengelompokkan data berdasarkan pertimbangan peneliti, sesuai dengan tujuan dan masalah penelitian. Tabulasi dengan menggabungkan data yang diperoleh, sebagai bahan interpretasi hasil, disajikan bersama kesesuaian dengan teori yang saling berhubungan dan saling mendukung sebagai laporan hasil penelitian. Peneliti menjelaskan dengan mendeskripsikan data yang dihasilkan dari proses penelitian, melakukan analisis data dengan tehnik deskriptif kualitatif, yaitu analisis yang menggambarkan keadaan atau fenomena dengan kata-kata atau kalimat, kemudian dipisah-pisahkan berdasarkan data yang terkumpul kemudian akan disimpulkan. Penelitian dilakukan dengan adanya sura ijin pengumpulan data penelitian kepada Kepala Desa Jagin dan ijin penelitian dari Bappeda Provinsi NTB.

\section{HASIL PENELITIAN DAN PEMBAHASAN}

\section{A. Hasil Penelitian}

Data Tahun 2019 di Kecamatan Kediri: Jumlah perempuan yang menikah < 21 tahun di Kecamatan Kediri: 1) Jagaraga Indah 26 kasus, 2) Ombe Baru 18 Kasus, 3) Kediri 4 Kasus, 4) Kediri Selatan 7 kasus, 5) Montong Are 13 kasus, 6) Gelogor 3 kasus, 7) Rumak 20 kasus, 8) Banyumulek 5 kasus dan 9) Dasan Baru 3 kasus (Data sekunder:DP2KBP3A Kabupaten Lombok Barat). Wadah kegiatan remaja yang lain dengan dibentuknya Forum Anak Desa (FAD) dan Kelompok Perlindungan Anak Desa (KPAD). Semua kegiatan, rencananya akan difasilitasi tempat di Kantor Desa seperti yang disampaikan oleh Kepala Dusun Tinggar Karang Anyar pada saat proses wawancara bersama Kepala Desa Jagin. Berdasarkan hasil observasi lokasi dalam proses penelitian, Kelompok DW Desa Jagin tidak difasilitasi dengan ruangan tersendiri, tidak ada struktur organisasi, dokumentasi rencana dan pelaksanaan kegiatan Kelompok DW Desa Jagin. Dalam alur mekanisme layanan perlindungan anak belum nampak keterlibatan Kelompok DW. 
Gambar 1. Alur Mekanisme Layanan Perlindungan Anak Desa Jagin

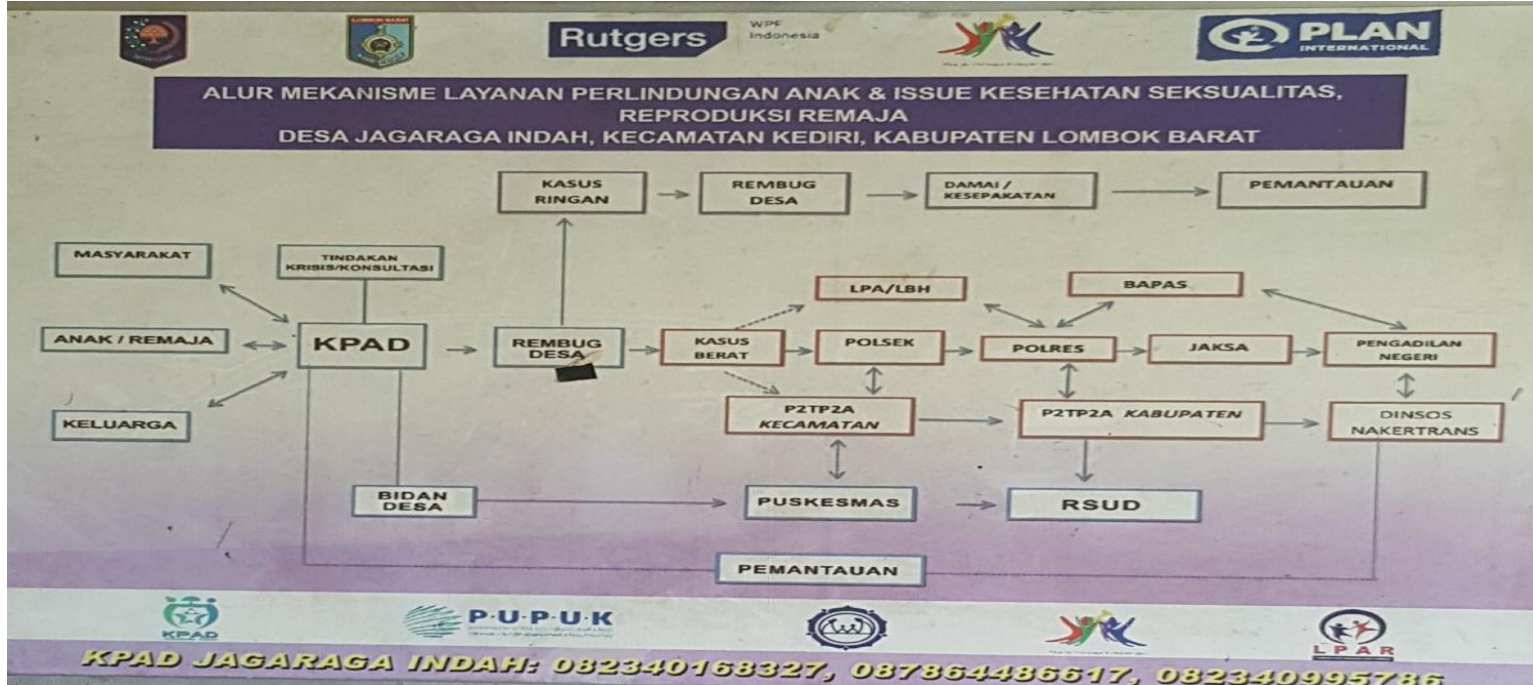

Tabel 1. Jumlah Remaja di Desa Jagaraga Indah

\begin{tabular}{|c|c|c|c|}
\hline No & $\begin{array}{c}\text { Laki-Laki } \\
\text { (orang) }\end{array}$ & $\begin{array}{r}\text { Perempuan } \\
\text { (orang) }\end{array}$ \\
\hline 1 & 425 & 391 & SMP \\
\hline 2 & 170 & 145 & SMA \\
\hline Jumlah & 595 & 536 & 1.131 \\
\hline
\end{tabular}

Tabel 2. Distribusi Jumlah Responden Berdasarkan Usia

\begin{tabular}{|c|l|c|c|}
\hline No & \multicolumn{1}{|c|}{$\begin{array}{c}\text { Usia } \\
\text { (Tahun) }\end{array}$} & $\begin{array}{c}\text { Frekuensi } \\
\text { (n) }\end{array}$ & $\begin{array}{c}\text { Prosentase } \\
\text { (\%) }\end{array}$ \\
\hline 1 & $20-24$ & 3 & 15 \\
\hline 2 & $25-29$ & 3 & 15 \\
\hline 3 & $\geq 30$ & 14 & 70 \\
\hline & TOTAL & 20 & 100 \\
\hline
\end{tabular}

Tabel 2. Menunjukkan bahwa usia dari 20 peserta PKBR, terbanyak pada usia $>30$ th yaitu 14 responden (70\%). Usia 20- 24 tahun 3 responden (15\%)

Tabel 3. Distribusi Jumlah Responden Berdasarkan Pekerjaan

\begin{tabular}{|c|l|c|c|}
\hline No & \multicolumn{1}{|c|}{ Jenis Pekerjaan } & Frekuensi (n) & Prosentase (\%) \\
\hline 1 & Ibu Rumah Tangga & 11 & 55 \\
\hline 2 & Tani & 3 & 15 \\
\hline 3 & Wirausaha & 4 & 20 \\
\hline 4 & Karyawan & 2 & 10 \\
\hline & TOTAL & 20 & 100 \\
\hline
\end{tabular}

Tabel 3.Menunjukkan bahwa jenis pekerjaan dari 20 peserta PKBR, terbanyak sebagai IRT yaitu 11 responden (55\%), selanjutnya wirausaha sebanyak 4 responden (20\%) yang terdiri dari 3 orang pedagang dan 1 orang pengusaha kecil di rumah.

Jenis kelamin 20 peserta PKBR adalah perempuan (100\%) dengan status perkawinan, 20 peserta PKBR sudah kawin (100\%) dan persepsi dari 20 peserta PKBR adalah baik (100\%) terhadap pencapaian tujuan PKBR 


\section{b. Pembahasan}

\section{Kecamatan Kediri. \\ 1. Persepsi peserta PKBR sebagai upaya PUP Kelompok DW, Desa Jagaraga Indah di}

Persepsi sebagai proses akhir dari pengamatan yang diawali dari proses pengindraan yang menyebabkan individu menyadari tentang sesuatu. Hal ini menurut (Notoatmodjo S. D., 2010) ${ }^{14}$ dapat mempengaruhi sikap yang dipengaruhi oleh aspek kognitif, aspek afektif dan aspek konaktif. Menurut (Sobur, 2003) $)^{15}$ persepsi merupakan bagian dari keseluruhan proses yang menghasilkan tanggapan setelah rangsangan diterapkan kepada manusia. Dari segi psikologis dikatakan bahwa tingkah laku seseorang merupakan fungsi dari cara dia memandang. Oleh karena itu, untuk mengubah tingkah laku seseorang harus dimulai dengan mengubah persepsinya. Dari hasil penelitian, bahwa persepsi dari 20 peserta PKBR di Desa Jagin terhadap pencapain tujuan PKBR dalam katagori baik. Dari 20 peserta PKBR mengetahui pentingnya peningkatan keterampilan dan pengembangan kreativitas remaja itu sendiri akan memberikan upaya pengembangan ekonomi dan mendapatkan dukungan dari dirinya sendiri dan sosial masyarakat sekitarnya. Hal ini akan mendorong sikap untuk memotivasi diri, teman/orang terdekat dan lingkungannya dalam upaya meningkatkan keterampilan dan kreativitas remaja dalam upaya meningkatkan ekonomi secara mandiri maupun berkelompok, selanjutnya akan menimbulkan kesadaran berperilaku pada remaja untuk setiap harinya berupaya dan melakukan kegiatan yang bermanfaat bagi kehidupan dirinya, sehingga dapat mengesampingkan pemikiran untuk menikah. Kebutuhan keterampilan dan kreativitas remaja dalam situasi sulit mendapatkan modal dan lapangan pekerjaan, sehingga remaja akan mengarahkan perilakunya untuk berusaha dalam bersinergi dengan administrasi desa, lingkungan dan masyarakat di sekitarnya.

\section{Pelaksanaan Kegiatan, Setelah PKBR.}

Program atau upaya Dialog Warga merupakan salah satu pendekatan dalam rangka peningkatan kesadaran pada masyarakat yang berfokus pada kapasitas dan kebutuhan komunitas itu sendiri, sehingga dengan metode DW melakukan elaborasi kapasitas dan kepentingan komunitas dengan asumsi utama adalah kita meyakini bahwa masyarakat pada dasarnya telah mempunyai pengetahuan maupun pengalaman untuk mengatasi persoalan-persoalan yang menjadi keprihatinan dan mereka rasakan bersama, dimana tujuan dari DW adalah untuk mengembangkan dan meningkatkan kompetensi komunitas dalam menangani isu-isu hak asasi perempuan dan kesetaraan laki-laki dan perempuan yang mereka anggap penting. Prinsip dasar agar proses DW dapat menghasilkan perubahan yang diharapkan antara lain: berbasis hak asasi, kesetaraan, apresiatif dan memberdayakan (Fadjar, Aplikasi Dialog Warga dalam upaya Pendewasaan Usia Perkawinan di NTB, 2019) ${ }^{16}$. Peserta PKBR 100\% perempuan, dengan distribusi responden berdasarkan pekerjaan 55\% adalah ibu rumah tangga, 20\% adalah wirausaha dengan 3 orang menjadi pedagang di pasar dan 1 orang mengelola usaha kecil di rumah.

Pemilihan peserta PKBR perlu dipertimbangkan dengan cermat, menetapkan kriteria yang diharapkan nantinya mempunyai kesesuaian dengan tujuan dari kegiatan itu sendiri yang ingin dicapai, yaitu memberikan penguatan pengetahuan, serta keterampilan untuk pembangunan ekonomi pada anak-anak remaja pra-nikah, usia dibawah 21 tahun sehingga siap membina rumah tangga guna membangun keluarga yang harmonis dan berkualitas. Memberikan peluang yang sama pada remaja laki-laki dan perempuan, aktif dalam kelompok remaja yang merupakan salah satu komponen terbentuknya kelompok dialog warga. Banyaknya remaja di Desa Jagin dengan aktivitas pokoknya sebagai pelajar, perlu menjadi pertimbangan tersendiri dalam menetapkan waktu dan lama pelaksanaan kegiatan. Pola kehidupan di desa juga perlu dipertimbangkan, ketika melibatkan peran serta dari ibu rumah tangga. Peran ibu rumah tangga di desa secara konvensional banyak terlibat dalam kesibukannya di rumah dalam mengelola rumah tangganya. Seorang peserta PKBR yang mengelola usaha kecil di rumah hanya bisa melibatkan remaja sekitarnya dalam tahap penjualan produksinya. 
3. Tindak lanjut Kelompok DW Desa Jagaraga Indah setelah PKBR dalam upaya PUP.

Dialog Warga dalam penerapannya dengan menggunakan pendekatan Appreciative Inquiry (AI), yaitu berangkat dari asumsi bahwa dalam kondisi manapun, masyarakat mempunyai banyak kemampuan, kapasitas dan sumberdaya yang harus ditemukenali dan diaktifkan, terbangun dari kesadaran dan kekayaan dan rasa berdaya serta keprihatinan dan kepedulian terhadap isu yang ingin diatasi. Prinsip apresiatif dalam hal ini menempatkan manusia, kemampuan dan kebutuhan manusia dan komunitas sebagai pusat perubahan itu sendiri. Memperhatikan beberapa prinsip dasar agar Metode DW mendapatkan hasil sesuai dengan harapan, antara lain: prinsip berkesinambungan dimana dialog yang dilakukan dapat terus berlanjut sehingga menggulirkan perubahan-perubahan lain yang berarti tanpa ketergantungan pada pihak luar dan prinsip berorientasi perubahan yaitu dialog yang dilakukan dalam kelompok tidak berhenti sebatas wacana namun dapat ditindaklanjuti dan menghasilkan perubahan yang nyata.

Pendewasaan Usia Perkawinan (PUP) adalah upaya untuk meningkatkan usia pada perkawinan pertama, sehingga mencapai usia ideal pada saat perkawinan. PUP bukan sekedar menunda sampai usia tertentu saja tetapi mengusahakan agar pernikahan dilakukan pada pasangan yang sudah siap/dewasa dari secara ekonomi, kesehatan, mental/psikologi. Faktor ekonomi dimana karena kondisi ekonomi yang memprihatinkan membuat pelaku pernikahan dini memutuskan untuk menikah $\left(\right.$ Khaerani, 2019) ${ }^{17}$. Tujuan program pendewasaan usia perkawinan adalah memberikan pengertian dan kesadaran kepada remaja agar didalam merencanakan keluarga, mereka dapat mempertimbangkan berbagai aspek yang berhubungan dengan kehidupan berkeluarga, kesiapan secara fisik, mental, emosional, pendidikan, sosial, ekonomi serta menentukan jumlah dan jarak kelahiran (Direktorat, 2012) ${ }^{18 .}$ Tujuan PUP seperti ini berimplikasi pada perlu adanya peningkatan usia kawin pertama yang lebih dewasa.

Sesuai SE. Gubernur usia ideal Usia Kawin Pertama (UKP) menikah bagi laki-laki dan perempuan minimal 21 tahun. Peserta PKBR 70\% berusia > 30 tahun, 15\% berusia $20-24$ tahun. Berdasarkan permasalahan upaya PUP di Provinsi NTB, maka yang dilaksanakan Pemerintah Provinsi NTB melalui Dinas P3AP2KB Provinsi NTB adalah kegiatan untuk meningkatkan potensi atau sumber daya manusia, khususnya remaja yang berumur dibawah 21 tahun. Diperlukan adanya dukungan yang berkesinambungan. Memfasilitasi dan memberikan kesempatan pada remaja untuk dapat meningkatkan potensi dirinya, tidak menjadikan ketergantungan pada pihak luar dan berorientasi pada adanya suatu perubahan, khususnya upaya meningkatkan usia kawin pertama. Belum nampak adanya tindaklanjut yang berkesinambungan dari kegiatan PKBR yang telah dilaksanakan, terutama dalam upaya pemberdayaan ekonomi remaja. Belum adanya pemberdayaan Kelompok DW dalam alur mekanisme layanan perlindungan anak, Peserta $85 \%$ berusia 20 tahun s/d $>30$ tahun dengan status sudah kawin semua. 26 kasus perkawinan perempuan usia $<21$ tahun di Desa Jagin pada tahun 2019. Hingga kini peraturan daerah tentang pencegahan pernikahan anak belum dimiliki oleh pemerintah provinsi NTB, maka dapat diduga bahwa kebijakan pencegahan pernikahan anak tidak memiliki pijakan dasar hukum yang memadai. Pada akhirnya kebijakan pencegahan pernikahan anak di NTB tidak mampu mendapatkan hasil yang maksimal (Karyati, 2019) ${ }^{19}$

\section{Efektivitas Pendidikan Keterampilan Bagi Remaja dalam upaya PUP Kelompok DW, Desa Jagin di Kecamatan Kediri.}

Pendekatan Tujuan (Goal Approach), berfokus pada tingkat dimana suatu organisasi mencapai tujuannya (Griffin, 2004) ${ }^{20}$. Efektivitas adalah keaktifan, daya guna, adanya kesesuaian dalam suatu kegiatan orang yang melaksanakan tugas dengan sasaran yang dituju. Efektivitas pada dasarnya menunjukkan pada taraf tercapainya hasil, suatu keadaan yang menunjukkan sejauh mana rencana dapat tercapai. Semakin banyak rencana yang dapat dicapai, semakin efektif pula kegiatan tersebut, sehingga kata efektivitas dapat juga diartikan sebagai tingkat keberhasilan yang dapat dicapai dari suatu cara atau usaha tertentu sesuai dengan tujuan yang hendak dicapai. Efektivitas menunjukkan keberhasilan dari segi tercapai tidaknya sasaran yang telah ditetapkan. Jika hasil kegiatan semakin mendekati sasaran, berarti makin tinggi efektivitasnya. Model pendekatan tujuan lebih fokus pada 
tingkat dimana suatu organisasi mencapai tujuannya (Othenk, 2008) ${ }^{21}$. Persepsi dari peserta PKBR adalah baik (100\%) terhadap pencapaian tujuan PKBR. Tujuan Pengembangan Kelompok Dialog Warga di masyarakat dalam rangka peningkatan keterampilan remaja, antara lain: 1) Memberikan penguatan pengetahuan, serta keterampilan untuk pembangunan ekonomi pada anak-anak remaja pra-nikah, usia dibawah 21 tahun sehingga siap membina rumah tangga guna membangun keluarga yang harmonis dan berkualitas, dan 2) Mendapatkan dukungan sosial bagi anak-anak remaja usia dibawah 21 tahun dalam rangka peningkatan usia perkawinan. Peserta PKBR yang ada rata-rata dalam rentang usia 25 tahun $\mathrm{s} / \mathrm{d}>30$ tahun (85\%), dimana dengan usia $<21$ tahun hanya 1 orang. Status pekerjaan sebagai IRT 55\% dan semua peserta $100 \%$ adalah perempuan dengan status perkawinan $100 \%$ sudah kawin. Kondisi ini tidak memberikan gambaran adanya pengembangan keterampilan dari remaja di Desa Jagin dalam upaya pembangunan ekonomi pada remaja. Data tahun 2019, perkawinan perempuan usia $<21$ tahun ada 26 kasus.

\section{KESISIMPULAN}

Berdasarkan pembahasan hasil penelitian, simpulan dari penelitian ini adalah sebagai berikut:

a. Adanya ketidak sesuaian pelaksanaan dengan sasaran yang dituju, menyebabkan tidak tercapainya tujuan PKBR, sehingga PKBR menjadi tidak efektiv terhadap upaya PUP di Desa Jagin

b. Ketidak berhasilan mencapai tujuan PKBR yang ditetapkan, sehingga belum mampu memberikan penguatan keterampilan untuk pembangunan ekonomi remaja dalam upaya PUP

c. Belum adanya tindaklanjut yang berkesinambungan dari kegiatan PKBR, khususnya dalam upaya pemberdayaan ekonomi remaja, sehingga data tahun 2019 di Desa Jagin masih ada 26 kasus untuk perkawinan perempuan usia $<21$ tahun

\section{DAFTAR PUSTAKA}

\section{Jurnal}

Puji Lestari. (2017). Strategi dinas pengendalian penduduk dan keluarga berencana dalam mengkampanyekan pendewasaan perkawinan terhadap remaja Ponorogo. Jurnal Universitas Muhammadiyah Ponoroga. Retreived from http://studentjournal.umpo.ac.id/index.php/IJGCS/article/view/100

Siti Nurul Khaerani. (2019). Faktor ekonomi dalam pernikahan dini pada masyarakat sasak Lombok. Jurnal Qawwam, 13(1),. Retreived from https://journal.uinmataram.ac.id/index.php/qawwam/article/view/1619

Sri Karyati. (2019). Kebijakan pencegahan pernikahan anak di Provinsi NTB pasca berlakunya UU no.16 tahun 2019 tentang perubahan UU no.1 tahun 1974 tentang perkawinan. Jurnal UnizarLawReview, 2(2),. Retreived from https://e-journal.unizar.ac.id/index.php/ulr/index

\section{Buku}

Tim Koordinasi Pengembangan GEN. (2017). Pedoman Pelaksanaan Program Generasi Emas NTB (GEN) 2025. Mataram.

BP3AKB Provinsi NTB. (2015). Bunga Rampai Praktek-Praktek Terbaik Pencegahan Perkawinan Dini. BP3AKB

BP3AKB, GTZ-SWR. (2011). Dialog Warga untuk Penguatan Hak Perempuan dan Kesetaraan Gender: Buku Panduan Bagi Fasilitator Desa. Jakarta. GTZ

Mulyadi Fadjar. (2019). Prosiding temu karya tulis ilmiah widyaiswara kesehatan. (Anita Basuki.). Jakarta: Pusat pelatihan SDM kesehatan.

Mulyadi Fadjar. (2019). Aplikasi dialog warga dalam upaya pendewasaan usia perkawinan di NTB. (Yen Kusnita.). Mataram: Pustaka Bangsa. 
Notoatmodjo, Soekidjo. (2012). Metodologi Penelitian Kesehatan. Jakarta: Rineka Cipta.

Arikunto. (2006). Prosedur Penelitian Metodologi Penelitian Suatu Pendekatan Praktik. Jakarta: Rineka Cipta.

Setiadi. (2007). Konsep dan Penulisan Riset Keperawatan. Yogyakarta: Graha Ilmu.

Sobur. (2003). Psikologi Umum. Bandung: Pustaka Setia.

Direktorat Bina Ketahanan Remaja. (2012). Materi pegangan kader tentang binmbingan dan pembinaan keluarga berencana. Jakarta: BKKBN.

Griffin. (2004). Manajemen. Jakarta: Erlangga.

\section{Skripsi (Undergraduated Thesis), Tesis (Thesis), Disertasi (Dissertation)}

Mazdaif, Y. (2014). Pengaruh penyuluhan pendewasaan usia perkawinan terhadap sikap tentang pernikahan dini siswa kelas XI SMAN I Dlingo. Skripsi. Yogyakarta: Sekolah Tinggi Ilmu Kesehatan 'Aisyiyah Yogyakarta. Indonesia.

Sumerah. (2019). Sembeq sengeteng (jampi pengikat) sebagai upaya pendewasaan usia perkawinan (studi kasus di Desa Wakan Jerowaru Lombok Timur). Undergraduated thesis. Mataram: Universitas Islam Negeri Mataram. Indonesia.

\section{Artikel Online atau Artikel dari Website dengan Author dan Tanpa Author}

TEMPO.CO, (2015), NTB, Provinsi Pertama Atur Pendewasaan Usia Perkawinan.Tersedia Online: (https://nasional.tempo.co/read/677284/ntb-provinsi-pertama-atur-pendewasaan-usiaperkawinan)(22 Juni 2015)

Othenk. (2008). Efektivitas dan landasan teori efektivitas. Retrieved from http://literaturbook.blokspot.co.id.

\section{Laporan}

DP3AP2KB Provinsi NTB. (2018). Laporan kegiatan pengembangan metode dialog warga di masyarakat dalam rangka peningkatan peningkatan keterampilan remaja tingkat kabupaten/kota se NTB tahun 2018. Mataram.

Peraturan Pemerintah atau Undang-Undang

Pemprov NTB. (2014). Surat Edaran Nomer 180/1153/Kum: tentang PUP. Mataram. 